\title{
Characterization, Mapping and Catheter Ablation of Atrial Tachycardia with Prior Atriotomy
}

Bin Luo ${ }^{1}$, Xiaogang Guo ${ }^{1}$, Qi Sun ${ }^{1}, \mathrm{Xu} \mathrm{Liu}^{2}$, Jiandu Yang ${ }^{1}$, Huiqiang Wei ${ }^{1}$, Gongbu Zhou ${ }^{3}$ and Jian Ma ${ }^{\text {* }}$

${ }^{1}$ The State Key Laboratory of Cardiovascular Disease, Arrhythmia Center, Fuwai Hospital, National Center for Cardiovascular Diseases, Chinese Academy of Medical Sciences and Peking Union Medical College, Beijing, P.R China

${ }^{2}$ Department of Cardiology, Peking Anzhen Hospital, Beijing, P.R China

${ }^{3}$ Department of Cardiology, Peking University Third Hospital, Beijing, P.R China

*Corresponding author: Jian Ma, The State Key Laboratory of Cardiovascular Disease, Arrhythmia Center, Fuwai Hospital, National Center for Cardiovascular Diseases, Chinese Academy of Medical Sciences and Peking Union Medical College, 100037 Beijing, P.R China, Tel: 861088398435; E-mail: majian_fuwai@126.com

Received: March 19, 2018; Accepted: March 28, 2018; Published: March 30, 2018

Copyright: (c) 2018 Luo B, et al. This is an open-access article distributed under the terms of the creative commons attribution license, which permits unrestricted use, distribution, and reproduction in any medium, provided the original author and source are credited.

\section{Abstract}

Introduction: The aim of this study was to develop bidirectional block of intra-atrial reentrant tachycardias (IARTs) late after the repair of congenital heart disease (CHD) using pace-map and entrainment mapping.

Methods and results: There were 106 patients enrolled in this study. These patients were divided into two groups as giant right atrium (RA) group and non-giant RA group based on their RA volume measured by Carto. All patients have performed activation and entrainment mapping among these patients, 24 (22.6\%) of Giant RA group had dual-loop reentry and 82 patients had single loop reentry. 94 patients $(88.7 \%)$ found out the gaps by pace-map in SR. Linear ablation was successful in 105 patients (99\%). During a mean follow-up period of $105 \pm 34$ months the success rate of IARTs was $66 \%$, there were significantly different in these two groups $(P<0.01)$. Seven $(6.6 \%)$ patients in Giant RA group undergone redo procedure.

Conclusion: Entrainment mapping in tachycardia and pace-map combined with three-dimensional electroanatomic mapping can elaborate the mechanism of complex re-entry circuits and critical isthmuses as targets for ablation. Pace-map in SR may be a good method for seeking the gap of ablation line to be bidirectional block for linear ablation IARTs.

Keywords: Atrial tachycardia; Entrainment mapping; Pace-map; Congenital heart disease

\section{Introduction}

Post-surgical atrial tachycardia (AT) always happened after congenital heart disease repairment. Anti-arrhythmia drugs (AADs) had limited effects for this kind of ATs. It could only be cured by radiofrequency catheter ablation (RFCA). The success rate for different kinds of post-surgical AT are various [1-10]. The three-dimensional mapping and entrainment mapping have been demonstrated to be useful for reveal of the tachycardia mechanism [11]. The RA volume among the congenital heart disease (CHD)patients was usually larger as usual, which could affect the outcome of AT ablation. The recurrence rate was higher in the IART patients with larger RA volume and low-voltage areas $[12,13]$. It was usually gaps in the ablation line for Giant RA, which led to IART recurrence. The aim of this study was therefore to evaluate the characteristics of mapping and ablation of post-surgical AT with giant RA and decreased the recurrence of IART by pace-map for seeking the gaps.

\section{Methods}

\section{Patient selection}

Consecutive CHD patients with prior atriotomy undergoing AT ablation using electroanatomic mapping between January 2012 and
December 2016 were selected for this study. Patients were referred to RFCA if they had multiple episodes of AT despite under control of at least one antiarrhythmic drug. Because we only focus on evaluating electroanatomic features of the RA, patients with Mustard/Senning repair were excluded as their atrial baffles distort RA geometry. This study was approved by the institutional ethics committee, and all subjects provided informed consent.

\section{Electrophysiological study and electroanatomic mapping and entrainment mapping}

Class I and III AADs were withheld for at least five half-lives, except for amiodarone, which was discontinued at least two weeks before the procedure. If the patient was not in $\mathrm{AT}$ at the beginning of the procedure or it was terminated during catheter placement, AT was induced, most commonly with rapid atrial pacing. Electro anatomical mapping (EAM) was performed using the CARTO system (Carto 3 or Carto XP, Biosense Webster Inc., Diamond Bar, CA, USA) for all patients. For each patient, a decapolar catheter was placed in the coronary sinus (CS) and a deflectable duodecapolar mapping catheter (Halo ${ }^{m}$, Biosense Webster Inc.) was always placed along with the tricuspid annular (TA) with the distal poles positioned at 7 O'clock of $\mathrm{TA}$ in left anterior oblique (LAO) view. Fluoroscopy and signal characteristics were used to verify stable endocardial catheter contact before points were acquired. A $3.5 \mathrm{~mm}$ irrigated-tip Thermocool Navistar catheter (Biosense Webster Inc. Diamond Bar, CA, USA) was used for mapping and ablation. Activation map was reconstructed to 
define the nature of AT with surgical scar [14]. Local activation time was determined with bipolar electrogram. Scar tissue was identified when atrial potential signal presented as voltage $<0.1 \mathrm{Mv}[15]$. The location of incision was identified by a line of double potentials/ fragment potential with low voltage indicative for conduction block. Entrainment mapping at multiple sites was then performed to confirm the mechanism and to demonstrate the reentry of AT, with methods previously described [16,17]. Pacing mapping at multiple sites and post-pacing interval (PPI) were performed to demonstrate the bidirectional block of prior ablation line undergone redo procedure $[18,19]$. For the redo patients in the Giant RA group. Cavotricuspid isthmus (CTI) was the most common reason for recurrence. This may because of bad catheter contact in this particular group of patients with big RA volume. Pacing mapping at different multiple sites of TA and double potential of free wall RA and then PPI measurement was performed to find the gaps of prior linear ablation (Figure 1).

\section{Pace-map for seeking the gaps of ablation line}

The interval from the coronary sinus (CS) proximity stimulus to ablation distal tip was measured. The CS stimulus to distal ablation tip electrogram component represents the time to activation of the ipsilateral side of the ablation line. The pacing site was in the CS proximity, then ablation Large tip moved from the ablation line of TA to IVC. Finally, the shortest time in these pace-map points may be the gap of ablation line, which can have arrived at bidirectional block by RFCA this point (Figure 1).

\begin{abstract}
Ablation
The Thermo cool Navistar catheter (Biosense Webster Inc., Diamond Bar, CA, USA) was applied to deliver radiofrequency energy with temperature limited to $43^{\circ} \mathrm{C}-45^{\circ} \mathrm{C}$, power to $30 \mathrm{~W}-50 \mathrm{~W}$ and saline flow of $17 \mathrm{~mL} / \mathrm{min}-25 \mathrm{~mL} / \mathrm{min}$. CTI dependent atrial flutter ablation was performed with an ablation line connecting TA with inferior vena cava (IVC). A linear ablation connecting the incisional scar with anatomic barrier was created for scar dependent tachycardia ablation. The CTI and incision to IVC isthmus bidirectional block were validated with pacing manoeuvers as previously described [20,21]. The endpoints were as follows: (1) termination of AT during radiofrequency energy delivering, (2) noninducibility of any atrial arrhythmia at the end of procedure and (3) demonstration of bidirectional conduction block of each ablation line. If termination of tachycardia could not be achieved during procedure, current cardioversion was performed. And after sinus rhythm (SR) was restored, AADs were continued to maintain SR.
\end{abstract}

\section{Follow-up and redo procedure}

After successful ablation, we recommended to discontinue AADs in all patients. Every patient underwent clinical follow-up with $24 \mathrm{~h}$ Holter monitor at 3 and 12 months, and annually thereafter. Patients were also instructed to undergo ECG tests upon symptoms. All tachyarrthymias were recorded including recurrent AT and development of AF. Patients with recurrent AT were encouraged to perform redo procedure. During redo procedure, after mapping and ablation of the present AT using protocols described above, bidirectional block of previous ablation lines was also validated.
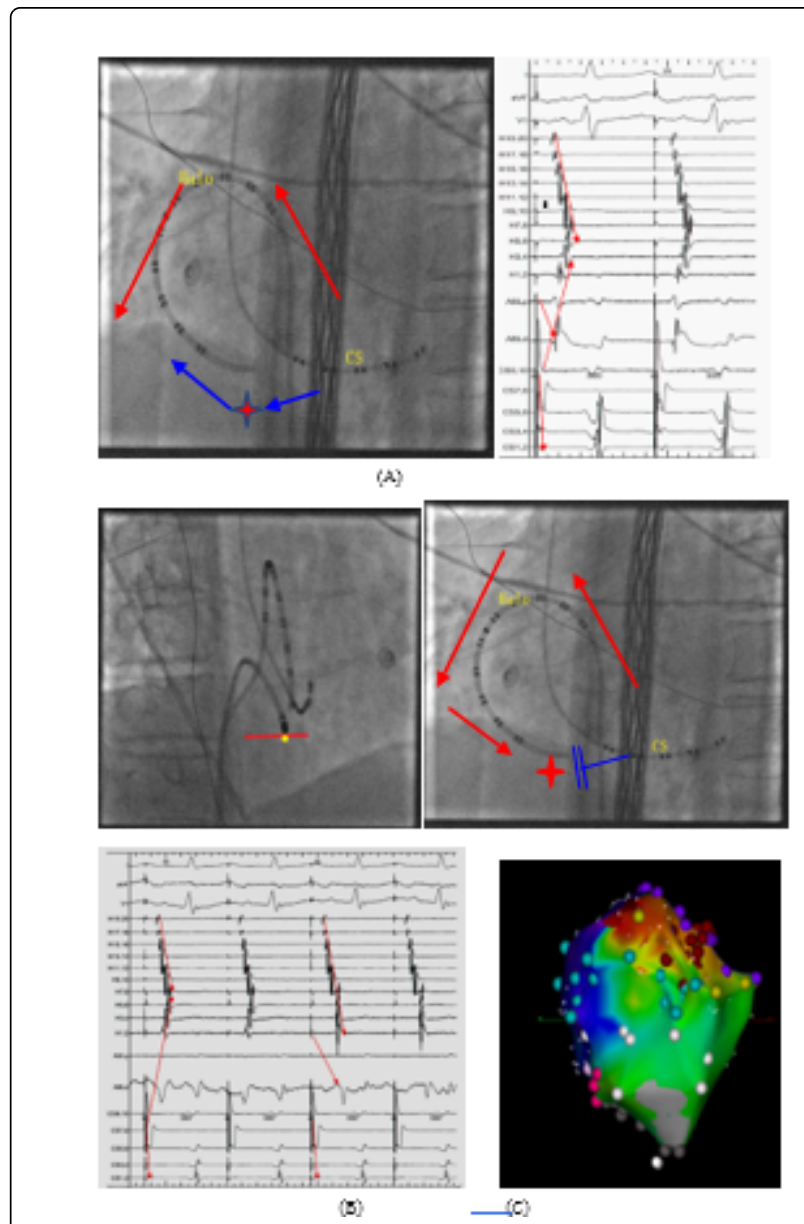

Figure 1: Coronary sinus (CS) pacing to find the leak point of ablation line of cavotricuspid isthmus (CTI). Intracardiac recordings from I, aVF, V1, Halo, CS. A: panels, left anterior oblique view (45) illustrating the position of the ablation catheter at the CTI and Halo catheter around the tricuspid annus (TA). Pacing from CS78 can result in the activation of wavefronts in the lateral right atrial (RA) wall (red and blue arrows). The shortest PPI (the interval from CS78 to Halo 12) was the leak point. B: Left anterior oblique (45) view, right anterior oblique (30), carto. C: illustrating the process of bidirectional block by ablated the leak point. Red marker denotes the target for radiofrequency (RF) catheter ablation; Green marker denotes double potential sites; purple marker denotes tricuspid annulus; White marker denotes inferior vena cava (IVC).

\section{Statistical analysis}

All statistics were performed using SPSS 19.0 (SPSS, Chicago, IL, USA). Normally distributed data were expressed as mean \pm SD and nonnormally distributed data as median (interquartile range). Comparisons between groups were made using unpaired Student's ttest or Mann-Whitney $U$ test for continuous variables and $\chi^{2}$ test or Fisher's exact test for categorical data. P-values $<0.05$, were considered statistically significant. 


\section{Results}

\section{Patient's characteristics}

There were 106 patients enrolled in this study. These patients were divided into two groups as Giant RA groups and non-Giant RA groups on the basis of their right atrial volume that it was not or more than $100 \mathrm{ml}$ [12]. There were 24 patients with enlarged right atrium included into the Giant RA group. The remaining patients were classified as non-Giant groups. Table 1 summarizes the baseline characteristics all the patients. The most common reason for open- heart surgery was atrial septum defect (ASD) in congenital heart disease (CHD), ventricular septum defect (VSD), and mitral valve (MV) disease, acquired heart disease(AHD), which was only operated via septal approach from right atrium in our series [14]. Other causes for surgery included Tetralogy of Fallot (ToF), Ebstein's anomaly, atrial tumor and aortic valve disease. AT appeared in average 17 (range, 130) months after cardiac surgery. The mean duration of tachycardia was $33 \pm 22$ (range, 1-65) months. Ebstein's anomaly is the most important reasons of enlargement right atrial. Table 2 summarizes the baseline characteristics of Giant RA groups (Table 2).

\begin{tabular}{|l|l|l|l|}
\hline Baseline characteristics & Non-Giant RA patients (N=83) & Giant RA patients (N=23) & P value \\
\hline Male gender (\%) & $49(59 \%)$ & $18(78.3 \%)$ & NS \\
\hline Mean age (yrs) & $45.4 \pm 15.4(8-77)$ & $44.7 \pm 11.7(26-65)$ & NS \\
\hline Tachycardia onset after surgery (mnths) & $7(1-76)$ & $17.1 \pm 9.6(1-30)$ & NS \\
\hline mean LV ejection fraction (\%) & $55 \pm 20(31-75)$ & $54 \pm 19(32-79)$ & NS \\
\hline mean LA size (mm) & $38 \pm 17(24-58)$ & $39 \pm 12(25-60)$ & NS \\
\hline duration of tachycardia & $29 \pm 25(2-55)$ & $31 \pm 22(1-63)$ & NS \\
\hline RA volume (ml) & $73.4 \pm 16.7(29.6-98.4)$ & $161.8 \pm 41.3(100.7-238.4)$ & P<0.01 \\
\hline RA: Right Atrial; LV: Left Ventricular; LA: Left Atrial & & & \\
\hline
\end{tabular}

Table 1: Patient and tachycardia characteristics.

\section{Electroanatomic mapping and procedural outcome of first ablation}

Persistent tachycardia was presented at the beginning of the procedure in all patients. All patients were mapped by Carto and entrainment mapping, $2422.6 \%$ patients had dual-loop reentry and 82 patients had single loop reentry (Figure. 2) Linear lesion was created between (1) incisional scar and IVC ( $n=26)$; (2) TA and IVC $(n=102)$; (3) septal patch and IVC $(n=2)$. (Figure 2). Bidirectional block of ablation line was observed in all. One patient was failure required by cardioversion because of atrial fibrillation during carto mapping. While the remaining patients was immediately succeeded after first procedure. During a mean follow-up period of $105 \pm 34$ months, the total success rate of first procedure was thus $66 \%$. All the patients undergoing redo procedure were no recurrent.

\section{Characteristics and ablation of giant atrial tachycardia}

In giant RA group, the average RA volume was $161.8 \pm 41.3 \mathrm{Ml}$ (Range 100.7-238.4) (Table 1). At the same time, they were usually TA regurgitation from mild to severe regurgitation (Table 2). The reason for open heart surgery and surgery procedure was in Table 2 . The average tachycardia cycle length was $249.6 \mathrm{~ms} \pm 38.1 \mathrm{~ms}$ (Range 210-280 ms).

\section{Characteristics of recurrent AT during redo procedures and entrainment mapping}

No one undergone redo procedure in the non-Giant RA group. While 6 patients in the Giant RA group undergone redo procedure and one patient undergone three procedures (Table 2). In these recurrence patients Nol and No 2 patients because of a new tachycardia which was related to the free wall scar of right atrial. The remaining 5 patients had the same tachycardia circuit but longer circle length than initial ablation.

For example, the No.19 patients who underwent three times procedures. During the first procedure, The ECG of tachycardia exhibited CTI dependent AFL (TACCW, TCL:236 ms Figures 3A-3D). she was confirmed to CTI-dependent flutter by carto mapping and entrainment mapping, which arrived at bidirection block at the end of procedure. After 6 months she was recurred atrial flutter but tachycardia cycle (TCL) was $280 \mathrm{~ms}$ (Figure 3C). The third-time operation that its TCL extended to $420 \mathrm{~ms}$ was held after one month of second ablation (Figure 3D). Entrainment mapping by closing to TA ventricular that TA was usually not good mapping because of right atrial enlargement. The patients undergone repeat ablation, which were carefully carto mapping and then entrainment mapping in the septal and Free wall of TA (Figure 3A). The post pacing interval was used to identify the leakage point with the previous procedure. At the end of operation, traditional method was used to verify the bidirectional block of cavotricuspid isthmus (CTI).

\section{Pace-map in sinus rhythm and find the leak point}

The tachycardias of all the patients can be terminated but not all be bidirectional block. Nighty-four patients (88.7\%) was used bypacemap to find the leak point (Figure 4). Close to ablation line bypacemap measure the scale from the ablation electrode to the proximal coronary sinus electrode. 
Citation: Luo B, Guo X, Sun Q, Liu X, Yang J, et al. (2018) Characterization, Mapping and Catheter Ablation of Atrial Tachycardia with Prior Atriotomy. J Cardiovasc Dis Diagn 6: 315. doi:10.4172/2329-9517.1000315

Page 4 of 7

\begin{tabular}{|c|c|c|c|c|c|c|c|c|c|c|c|c|c|}
\hline Number & Sex & $\begin{array}{l}\text { Age } \\
\text { (y) }\end{array}$ & $\begin{array}{l}\text { RA } \\
\text { volume } \\
\text { (ml) }\end{array}$ & $\begin{array}{l}\text { Reasons for } \\
\text { open heart } \\
\text { surgery }\end{array}$ & $\begin{array}{l}\text { Surgery } \\
\text { procedure }\end{array}$ & $\begin{array}{l}\mathrm{CL} \\
\text { (ms) }\end{array}$ & $\begin{array}{l}\text { Tachy- } \\
\text { cardia } \\
\text { onset } \\
\text { after } \\
\text { surgery } \\
\text { (y) }\end{array}$ & $\begin{array}{l}\text { TA regur- } \\
\text { gitation }\end{array}$ & $\begin{array}{l}\text { AFL } \\
\text { circuit }\end{array}$ & $\begin{array}{l}\text { Ablation } \\
\text { site }\end{array}$ & $\begin{array}{l}\text { Repeat } \\
\text { procedure }\end{array}$ & $\begin{array}{l}\text { Ablation } \\
\text { site }\end{array}$ & $\begin{array}{l}\text { Recurrence } \\
\text { AT CL (ms) }\end{array}$ \\
\hline 1 & $M$ & 43 & 110.98 & $\begin{array}{l}\text { Ventricular } \\
\text { septum } \\
\text { defect }\end{array}$ & $\begin{array}{l}\text { VSD closure } \\
\text { and Tricuspid } \\
\text { valve } \\
\text { replacement }\end{array}$ & 250 & 12 & $\mathrm{~N}$ & $\begin{array}{l}\text { one } \\
\text { loop }\end{array}$ & $\begin{array}{l}\mathrm{CTI}+\mathrm{RA} \\
\text { free wall }\end{array}$ & yes & $\begin{array}{l}\text { freewall } \\
\text { scar }\end{array}$ & 220 \\
\hline 2 & M & 38 & 148.31 & $\begin{array}{l}\text { Tetralogy of } \\
\text { Fallot }\end{array}$ & $\begin{array}{l}\text { Complete } \\
\text { repair }\end{array}$ & 210 & 30 & moderate & $\begin{array}{l}\text { dual } \\
\text { loop }\end{array}$ & $\begin{array}{l}C T I+R A \\
\text { free wall }\end{array}$ & no & $\begin{array}{l}\text { freewall } \\
\text { scar }\end{array}$ & 500 \\
\hline 3 & $\mathrm{~F}$ & 56 & 213.17 & $\begin{array}{l}\text { Mitral valve } \\
\text { disease }\end{array}$ & $\begin{array}{l}\text { Mitral valve } \\
\text { replacement }\end{array}$ & 250 & 20 & severe & $\begin{array}{l}\text { one } \\
\text { loop }\end{array}$ & CTI & yes & $\begin{array}{l}\text { TA } \\
\text { ventricular }\end{array}$ & 300 \\
\hline 4 & $\mathrm{~F}$ & 63 & 182.28 & $\begin{array}{l}\text { Mitral valve } \\
\text { disease }\end{array}$ & $\begin{array}{l}\text { Mitral valve } \\
\text { replacement }\end{array}$ & 280 & 12 & moderate & $\begin{array}{l}\text { one } \\
\text { loop }\end{array}$ & CTI & no & & \\
\hline 5 & M & 35 & 205.46 & $\begin{array}{l}\text { Ebstein's } \\
\text { anamoly and } \\
\text { Atrail septum } \\
\text { defect }\end{array}$ & $\begin{array}{l}\text { Tricuspid } \\
\text { valvuloplasty } \\
\text { and ASD } \\
\text { closure }\end{array}$ & 240 & 24 & N & $\begin{array}{l}\text { one } \\
\text { loop }\end{array}$ & CTI & yes & $\begin{array}{l}\text { TA } \\
\text { ventricular }\end{array}$ & 400 \\
\hline 6 & M & 42 & 135.09 & $\begin{array}{l}\text { Ventricular } \\
\text { septum } \\
\text { defect }\end{array}$ & VSD closure & 260 & 22 & moderate & $\begin{array}{l}\text { dual } \\
\text { loop }\end{array}$ & $\begin{array}{l}C T I+R A \\
\text { free wall }\end{array}$ & no & & \\
\hline 7 & $\mathrm{~F}$ & 48 & 118.36 & $\begin{array}{l}\text { Tetralogy of } \\
\text { Fallot }\end{array}$ & $\begin{array}{l}\text { Complete } \\
\text { repair }\end{array}$ & 210 & 22 & little & $\begin{array}{l}\text { dual } \\
\text { loop }\end{array}$ & $\begin{array}{l}\mathrm{CTI}+\mathrm{RA} \\
\text { free wall }\end{array}$ & no & & \\
\hline 8 & M & 65 & 159.71 & $\begin{array}{l}\text { Atrail septum } \\
\text { defect }\end{array}$ & ASD closure & 240 & 10 & moderate & $\begin{array}{l}\text { one } \\
\text { loop }\end{array}$ & $\begin{array}{l}\text { inscision } \\
\text { scar to IV } \\
\text { C }\end{array}$ & no & & \\
\hline 9 & $\mathrm{~F}$ & 63 & 100.76 & Atrial tumor & $\begin{array}{l}\text { Atrial } \\
\text { tumorectomy }\end{array}$ & 270 & 16 & $\mathrm{~N}$ & $\begin{array}{l}\text { dual } \\
\text { loop }\end{array}$ & $\begin{array}{l}C T I+R A \\
\text { free wall }\end{array}$ & no & & \\
\hline 10 & $M$ & 26 & 126.29 & $\begin{array}{l}\text { Atrail septum } \\
\text { defect and } \\
\text { Ebstein's } \\
\text { anamoly }\end{array}$ & ASD closure & 260 & 8 & little & $\begin{array}{l}\text { one } \\
\text { loop }\end{array}$ & CTI & no & & \\
\hline 11 & M & 33 & 111.96 & $\begin{array}{l}\text { Mitral valve } \\
\text { disease }\end{array}$ & $\begin{array}{l}\text { Mitral } \\
\text { valvuloplasty }\end{array}$ & 250 & 7 & little & $\begin{array}{l}\text { one } \\
\text { loop }\end{array}$ & CTI & no & & \\
\hline 12 & $M$ & 42 & 124.5 & $\begin{array}{l}\text { Atrail septum } \\
\text { defect }\end{array}$ & ASD closure & 240 & 1 & $\mathrm{~N}$ & $\begin{array}{l}\text { one } \\
\text { loop }\end{array}$ & CTI & no & & \\
\hline 13 & $M$ & 27 & 190.38 & $\begin{array}{l}\text { Atrail septum } \\
\text { defect }\end{array}$ & ASD closure & 250 & 15 & severe & $\begin{array}{l}\text { one } \\
\text { loop }\end{array}$ & CTI & yes & & 410 \\
\hline 14 & $M$ & 58 & 119.56 & $\begin{array}{l}\text { Mitral valve } \\
\text { disease }\end{array}$ & $\begin{array}{l}\text { Mitral } \\
\text { valvuloplasty }\end{array}$ & 270 & 4 & $\mathrm{~N}$ & $\begin{array}{l}\text { one } \\
\text { loop }\end{array}$ & CTI & no & & \\
\hline 15 & $M$ & 49 & 217.64 & $\begin{array}{l}\text { Ebstein's } \\
\text { anamoly }\end{array}$ & $\begin{array}{l}\text { Tricuspid } \\
\text { valvuloplasty }\end{array}$ & 240 & 2 & severe & $\begin{array}{l}\text { one } \\
\text { loop }\end{array}$ & CTI & yes & $\begin{array}{l}\text { TA } \\
\text { ventricular }\end{array}$ & 340 \\
\hline 16 & M & 47 & 218.8 & $\begin{array}{l}\text { Ventricular } \\
\text { septum } \\
\text { defect }\end{array}$ & VSD closure & 280 & 30 & severe & $\begin{array}{l}\text { one } \\
\text { loop }\end{array}$ & CTI & yes & \multicolumn{2}{|c|}{ TA ventricular } \\
\hline 17 & M & 32 & 1189 & $\begin{array}{l}\text { Ventricular } \\
\text { septum } \\
\text { defect }\end{array}$ & VSD closure & 260 & 30 & severe & $\begin{array}{l}\text { one } \\
\text { loop }\end{array}$ & CTI & no & & \\
\hline 18 & $M$ & 54 & 140.89 & $\begin{array}{l}\text { Ventricular } \\
\text { septum } \\
\text { defect }\end{array}$ & ASD closure & 260 & 15 & moderate & $\begin{array}{l}\text { one } \\
\text { loop }\end{array}$ & CTI & yes & & 360 \\
\hline
\end{tabular}


Citation: Luo B, Guo X, Sun Q, Liu X, Yang J, et al. (2018) Characterization, Mapping and Catheter Ablation of Atrial Tachycardia with Prior Atriotomy. J Cardiovasc Dis Diagn 6: 315. doi:10.4172/2329-9517.1000315

Page 5 of 7

\begin{tabular}{|c|c|c|c|c|c|c|c|c|c|c|c|c|c|}
\hline 19 & $\mathrm{~F}$ & 48 & 238.4 & $\begin{array}{l}\text { Ventricular } \\
\text { septum } \\
\text { defect }\end{array}$ & VSD closure & 236 & 23 & severe & $\begin{array}{l}\text { one } \\
\text { loop }\end{array}$ & CTI & yes & $\begin{array}{l}\text { TA } \\
\text { ventricular }\end{array}$ & $280 / 420$ \\
\hline 20 & $M$ & 32 & 189.2 & $\begin{array}{l}\text { Atrail septum } \\
\text { defect }\end{array}$ & ASD closure & 260 & 23 & moderate & $\begin{array}{l}\text { one } \\
\text { loop }\end{array}$ & CTI & no & & \\
\hline 21 & M & 39 & 157.8 & $\begin{array}{l}\text { Atrail septum } \\
\text { defect }\end{array}$ & ASD closure & 236 & 45 & moderate & $\begin{array}{l}\text { one } \\
\text { loop }\end{array}$ & $\mathrm{CTI}$ & no & & \\
\hline 22 & $M$ & 35 & 176.2 & $\begin{array}{l}\text { Atrail septum } \\
\text { defect }\end{array}$ & ASD closure & 250 & 12 & moderate & $\begin{array}{l}\text { one } \\
\text { loop }\end{array}$ & $\begin{array}{l}C T I+R A \\
\text { free wall }\end{array}$ & no & & \\
\hline 23 & $M$ & 54 & 212.5 & $\begin{array}{l}\text { Endocardial } \\
\text { cushions } \\
\text { defect }\end{array}$ & $\begin{array}{l}\text { Endocardial } \\
\text { cushions } \\
\text { repair }\end{array}$ & 238 & 27 & severe & $\begin{array}{l}\text { dual } \\
\text { loop }\end{array}$ & CTI & no & & \\
\hline
\end{tabular}

RA: Right Atrial; LV: Left Ventricular; LA: Left Atrial; VSD: Ventricular Septum Defect; ASD: Atrial Septum Defect; TA: Tricuspid Annulus; AFL: Atrial Flutter; AT: Atrial Tachycardia; CL: Cycle Length; N: No Regurgitation; IVC: Inferior Vein Cava

Table 2: Characteristics of Giant right atrial.

\section{Follow-up after the first procedure and redo procedures}

During a mean follow-up period of $105 \pm 34$ months, there were significantly different in these two groups $(\mathrm{P}<0.01)$. There were $7 / 23$ patients with recurrent AT in Giant atrial group, while no one recurrence in non-Giant group (Table 2). Only one patient in the Giant group had the third procedure. All the patients were sinus rhythm without AADs after redo procedure during follow-up.

\section{Complications}

No complications including cardiac tamponade, atrioventricular block and no vascular access complications needing surgical treatment and peri-procedural infection, bleeding and thromboembolism.

\section{Discussion}

In this study, the major findings were the following: (1) This Giant RA arrhythmia was found in $21.7 \%$ of the patients undergoing ablation for atrial macroreentry tachycardia with prior atriotomy. (2) Electroanatomic Mapping can help us understand the mechanism of Giant right atrial tachycardia and eliminate the arrhythmia. (3) Entrainment mapping and post pacing interval (PPI) may be a benefit method for redo procedure patients. (4) pace-map was a good technique for seek the gaps of ablation line.

\section{Entrainment manoeuvre and post pacing interval}

Entrainment mapping and carto mapping was used to delineate the complex re-entry circuits and mechanism of IART $(6,7,10)$. Electroanatomic mapping was used to map the tachycardia, and then Entrainment manoeuvre and post pacing interval (PPI) was used to certify how to reentry of AFL (Figure 3). When critical isthmuses were demonstrated, entrainment close to unexcitable areas that define the isthmus was used to determine whether they were in the circuit. Lineal ablation was applied to transect this isthmus to be bidirectional block of Cavotricuspid Isthmus (CTI).
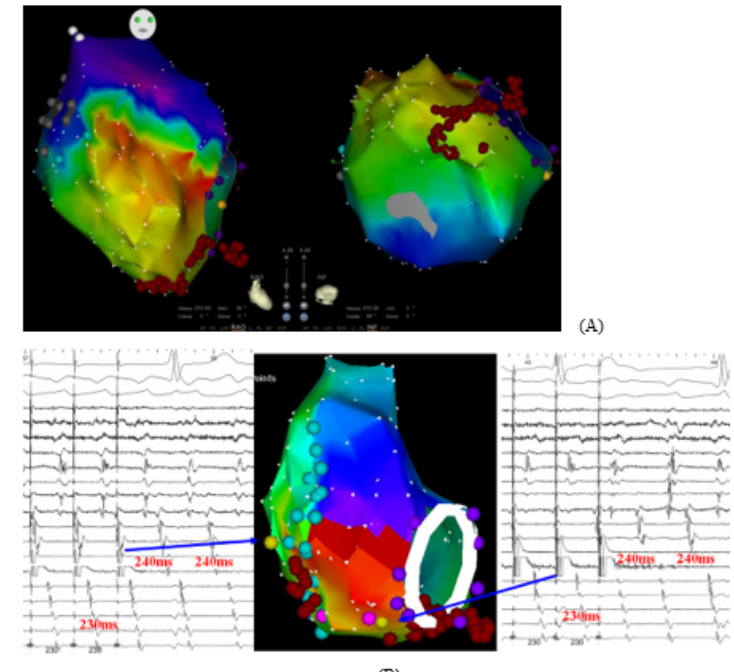

(B)

Figure 2: Three-dimentional mapping and entrainment mapping verified the reentry of atrial tachycardia (AT). (A) illustrates One loop of AT, (B) was dual loop. Yellow markers denote the entrainment mapping recording site; gray markers denote the low voltage recording site; red marker denotes the target for radiofrequency $(\mathrm{RF})$ catheter ablation; blue marker denotes double potential recording site; purple marker denotes tricuspid annulus.

\section{Pace-map was a good technique for seek the gap of ablation line}

Many patients undergone linear ablation, it was usually terminated but it usually could not be bidirectional block of ablation line owing to catheter unstablity, difficult anatomy and large right atrium. How to seek the gap ablation line that Pace-map through the ablation line may be a good method to tackle it. For example, After the right atrial Cavotricuspid Isthmus (CTI) ablated of CTI-Dependent Atrial Flutters (AFL), AFL was terminated but it was not often bidirectional block. The ablation catheter was located in the free wall of ablation line, and 
Citation: Luo B, Guo X, Sun Q, Liu X, Yang J, et al. (2018) Characterization, Mapping and Catheter Ablation of Atrial Tachycardia with Prior Atriotomy. J Cardiovasc Dis Diagn 6: 315. doi:10.4172/2329-9517.1000315

Page 6 of 7

then it compared with the interval between the coronary sinus and ablation catheter by coronary sinus proximal pacing 19 The ablation line arrived at bidirectional block to seek the gap of ablation line.

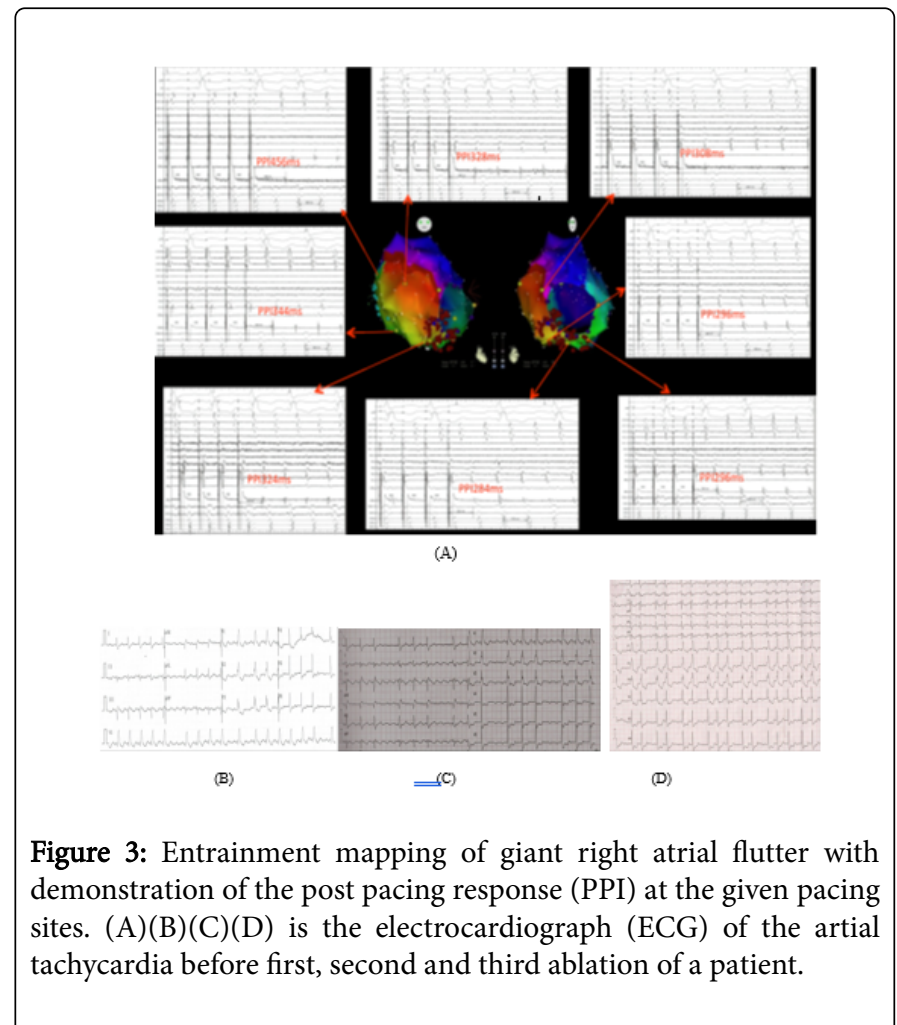

\section{Conclusion}

The Giant RA arrhythmia was found in $21.7 \%$ of the patients undergoing ablation for atrial macroreentry tachycardia with prior atriotomy. Electroanatomic Mapping can help us understand the mechanism of Giant right atrial tachycardia and eliminate the arrhythmia. Entrainment mapping and post pacing interval (PPI) may be a benefit method for redo procedure patients. Pace-map was a good technique for seek the gaps of ablation line.

\section{Limitation}

This was a retrospective analysis, no detailed data on ablation procedures were available and follow-up was not structured. The number of patients with ablation of IART and CTI-AFL were very low, and calculation of success rates and redo procedures highly influenced by single cases.

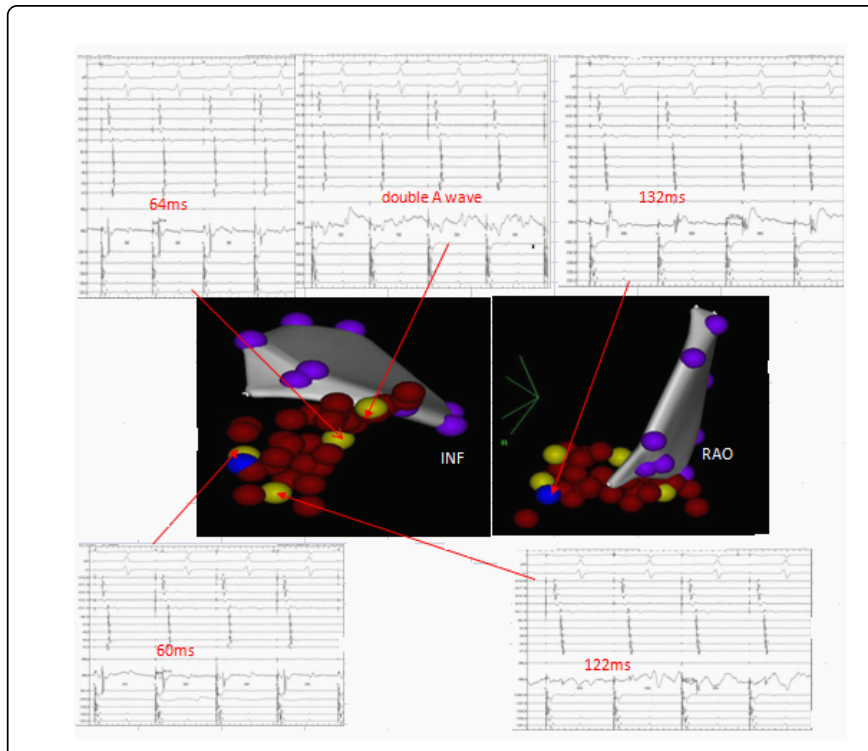

Figure 4: Looking for the leak point of linear ablation right atrial Cavotricuspid isthmus (CTI) by pace-map. Yellow markers denote the entrainment mapping recording site; red marker denotes the target for radiofrequency (RF) catheter ablation; blue marker denotes successful RFCA site; purple marker denotes tricuspid annulus.

\section{Declaration of Conflicts of Interest}

None.

\section{References}

1. Triedman JK, Saul JP, Weindling SN, Walsh EP (1995) Radiofrequency ablation of intra-atrial reentrant tachycardia after surgical palliation of congenital heart disease. Circulation 91: 707-714.

2. Van Hare GF, Lesh MD, Ross BA, Perry JC, Dorostkar PC (1996) Mapping and radiofrequency ablation of intra-atrial reentrant tachycardia after the Senning or Mustard procedure for transposition of the great arteries. Am J Cardiol 77: 985-991.

3. Kalman JM, VanHare GF, Olgin JE, Saxon LA, Stark SI, et al. (1996) Ablation of 'incisional' reentrant atrial tachycardia complicating surgery for congenital heart disease: Use of entrainment to define a critical isthmus of slow conduction. Circulation 93: 502-512.

4. Shah D, Ja“is P, Takahashi A, Hocini M, Peng JT, et al. (2000) Dual-loop intra-atrial reentry in humans. Circulation 101: 631-639.

5. Love BA, Collins KK, Walsh EP, Triedman JK (2001) Electroanatomic characterization of conduction barriers in sinus/atrially entrainmented rhythm and association with intra-atrial reentrant tachycardia circuits following congenital heart disease surgery. J Cardiovasc Electrophysiol 12: $17-25$.

6. Triedman JK, Alexander ME, Berul CI, Bevilacqua LM, Walsh EP (2001) Electroanatomic mapping of entrained and exit zones in patients with repaired congenital heart disease and intra-atrial reentrant tachycardia. Circulation 103: 2060-2065.

7. Reithmann C, Hoffmann E, Dorwarth U, Remp T, Steinbeck G (2001) Electroanatomical mapping for visualization of atrial activation in patients with incisional atrial tachycardias. Eur Heart J 22: 237-246.

8. Nakagawa H, Shah N, Matsudaira K, Overholt E, Chandrasekaran K, et al. (2001) Characterization of reentrant circuit in macroreentrant right 
Citation: Luo B, Guo X, Sun Q, Liu X, Yang J, et al. (2018) Characterization, Mapping and Catheter Ablation of Atrial Tachycardia with Prior Atriotomy. J Cardiovasc Dis Diagn 6: 315. doi:10.4172/2329-9517.1000315

Page 7 of 7

atrial tachycardia after surgical repair of congenital heart disease: Isolated channels between scars allow focal ablation. Circulation 103: 699-709.

9. Paul T, Windhagen-Mahnert B, Kriebel T, Bertram H, Kaulitz R, et al (2001) Atrial reentrant tachycardia after surgery for congenital heart disease: Endocardial mapping and radiofrequency catheter ablation using a novel, noncontact mapping system. Circulation 103: 2226-2271.

10. Delacretaz E, Ganz LI, Soejima K, Friedman PL, Walsh EP, et al. (2001) Multi-atrial macroreentry circuits in adults with repaired congenital heart disease: Entrainment mapping combined with three-dimensional electroanatomic mapping. J Am Coll Cardiol 37: 1665-1676.

11. Magnin-Poull I, De Chillou C, Miljoen H, Andronache M, Aliot E (2005) Mechanisms of right atrial tachycardia occurring late after surgical closure of atrial septal defects. J Cardiovasc Electrophysiol 16: 681-687.

12. Yap SC, Harris L, Downar E, Nanthakumar K, Silversides CK, et al. (2012) Evolvingelectroanatomic substrate and intra-atrial reentrant tachycardia late after Fontan surgery. J Cardiovasc Electrophysiol 23: 339-345.

13. Roten L, Lukac P, DE Groot N, Nielsen JC, Szili-Torok T, et al. (2011) Catheter ablation of arrhythmias in ebstein's anomaly: a multicenter study. J Cardiovasc Electrophysiol 22: 1391-1396.

14. Zhou G, Hu J, Guo X, Liu X, Yang J, et al. (2016) Very long-term outcome of catheter ablation of post-incisional atrial tachycardia: Role of incisional and non-incisional scar. Int J Cardiol 205: 72-80.

15. De Groot NM, Schalij MJ, Zeppenfeld K, Blom NA, Van der Velde ET, et al. (2003) Voltage and activation mapping: How the recording technique affects the outcome of catheter ablation procedures in patients with congenital heart disease. Circulation 108: 2099-2106.

16. Miyazaki H, Stevenson WG, Stephenson K, Soejima K, Epstein LM (2006) Entrainment mapping for rapid distinction of left and right atrial tachycardias. Heart Rhythm 3: 516-523.

17. Morton JB, Sanders P, Deen V, Vohra JK, Kalman JM (2002) Sensitivity and specificity of concealed entrainment for the identification of a critical isthmus in the atrium: relationship to rate, anatomic location and antidromic penetration. J Am Coll Cardiol 39: 896-906.

18. Shah D, Haissaguerre M, Takahashi A, Jais P, Hocini M (2000) Differential pacing for distinguishing block from persistent conduction through an ablation line. Circulation 102: 1517-1522.

19. Chen J, de Chillou C, Basiouny T, Sadoul N, Filho JDS, et al. (1999) Cavotricuspid isthmus mapping to assess bidirectional block during common atrial flutter radiofrequency ablation. Circulation 100: 25072513.

20. Jais P, Hocini M, Hsu LF, Sanders P, Scavee C, et al. (2004) Technique and results of linear ablation at the mitral isthmus. Circulation 110: 29963002.

21. Scaglione M, Riccardi R, Calo L, Donna P, Lamberti F, et al. (2000) Typical atrial flutter ablation: conduction across the posterior region of the inferior vena cava orifice may mimic unidirectional isthmus block. J Cardiovasc Electrophysiol 11: 387-395. 